\title{
Impact response and ballistic performances of graphitic foams
}

\author{
G. Janszen \& P. G. Nettuno \\ Politecnico di Milano, Dipartimento di Ingegneria Aerospaziale, Italy
}

\begin{abstract}
The demand for low weight structures that can achieve different structural, thermal and safety results is increasing in multiple engineering applications.

Graphitic foam, due to its low density, relatively easy machine tooling, stiffness and homogeneity can be a good choice for sandwich panel filling. Moreover, in spite of its brittle general behaviour, this kind of material, due to its cellular structure and mechanical behaviour, can have interesting ballistic properties by exploiting the compressive behaviour of the material. Subsequent impact against cell walls, as well as the strain rate dependency of the mechanical limits, leads to high energy absorption. Taking into consideration that there have been no studies about this topic, this research was oriented towards a macroscopic identification of the material performances. A numerical Ls-Dyna model was implemented on the basis of bibliographic research and several static characterization tests on foam samples. The model was developed based on a cellular material that could involve strain rate effects: strain rate dependent compressive stress-strain curves were developed based on micromechanical models typical of ceramic materials and backed out to fit a specific speed impact test.
\end{abstract}

A ballistic testing campaign was performed by measuring the response of two different foam density samples $\left(0.56 \mathrm{~g} / \mathrm{cm}^{3}\right.$ and $\left.0.24 \mathrm{~g} / \mathrm{cm}^{3}\right)$. The first type of ballistic test was performed using a spherical steel impactor with a diameter of $5 \mathrm{~mm}$ and mass of $0.5 \mathrm{~g}$. It collided perpendicularly with a $50 \mathrm{~mm} \times 50 \mathrm{~mm} \times$ $40 \mathrm{~mm}$ block of carbon foam at speeds of 240,210, and $75 \mathrm{~m} / \mathrm{s}$. Other tests in the same speed range were performed on a $400 \mathrm{~mm}$ x $400 \mathrm{~mm}$ x $40 \mathrm{~mm}$ reinforced carbon fibre panel hit by a $93 \mathrm{~g}$ and a $53 \mathrm{~g}$ steel cylindrical bullet (diameter $22 \mathrm{~mm}$, length $40 \mathrm{~mm}$ ). The results of a specific speed test were used to fit the model and then used to reproduce all other cases.

Very high agreement between the experimental results and the simulation was achieved.

Keywords: carbon foam, ballistic impacts. 


\section{Introduction}

The interest in materials capable of ensuring protection for ballistic impacts is justified by applications in the military, in civil transport and in many other fields. Usually, cellular materials allow better results than full dense solids in terms of kinetic energy dissipation achieved, and at the same time, the need for low-weight structures [1]. There is no wide application database of carbon foams employed as structural components, but simply a few suggestions concerning sandwich panels used in quasi-static conditions [2] and studies about hypervelocity impact protection for space vehicles [3]. For these reasons a complete investigation program has been developed and aimed to prove the foam kinetic energy dissipation capability in ballistic impacts. This program has been created to understand and model the mechanical behaviour of carbon foams in quasi static, as well as high strain-rate, regimes. Therefore, besides a wide experimental activity for the mechanical characterization, impact tests in the range of $200 \mathrm{~m} / \mathrm{s}$ with very different peculiarities were conducted. To perform numerical analyses and the experimental-numerical correlations, the explicit finite elements code Ls-Dyna was used. The experimental campaign was developed performing mono-axial quasi static tests on foams having two different densities $\left(240 \mathrm{~kg} / \mathrm{m}^{3}\right.$ and $\left.560 \mathrm{~kg} / \mathrm{m}^{3}\right)$. The ballistic tests were performed using a spherical steel impactor with a diameter of $5 \mathrm{~mm}$ and a mass of $0.5 \mathrm{~g}$, which perpendicularly collided, at speeds of $240 \mathrm{~m} / \mathrm{s}, 210 \mathrm{~m} / \mathrm{s}$ and $75 \mathrm{~m} / \mathrm{s}$, with a block of carbon foam of dimensions $50 \mathrm{~mm}$ x $50 \mathrm{~mm}$ x $40 \mathrm{~mm}$. Other tests were performed on a $400 \mathrm{~mm}$ x $400 \mathrm{~mm}$ x $40 \mathrm{~mm}$ reinforced carbon fibre panel hit by a $93 \mathrm{~g}$ and a $53 \mathrm{~g}$ steel cylindrical bullet (diameter $22 \mathrm{~mm}$, height $40 \mathrm{~mm}$ ).

The mechanical characterization tests were completed with confined compression, three point flexural tests and fracture toughness experiments. This development was needed to identify and use the correct material model in the computations. The substantial difference in the ballistic tests showed that, in spite of the limited fracture toughness, these foams were able to dissipate, in an efficient way, the kinetic energy of the spherical stainless steel bullets. Even if the foams showed a fragile nature, after the high speed impacts the dimensions of the damage were limited, and the strain evolved in a uniaxial way. In this case the material behaved properly like a foam. The crushing mechanism involved on a micromechanical and cellular scale caused bullet entrapment, a reduction of the impact velocity and controlled the rebound. On the other hand, the impact with a bullet of transversal dimension comparable to the thickness of the sandwich panel showed that the foam was less efficient in dissipating the kinetic energy of the impactor and the system experienced not just uniaxial, but also bending and tensile strains. By comparing these results with the quasi static characterization experiments it was possible to identify under which condition the material showed the typical behaviour of the foams. Under a confined loading condition, these foams presented energy absorption much higher than in the case of simple compression, due to the extended crushing plateau. Anyhow, this phenomenon was not in accordance with the results of the ballistic tests performed with the spherical bullet. Therefore, a micromechanical model used for ceramics, 
describing crack evolution under dynamic loading, was adopted. The reason for using this model is due to some common points between the ceramics and the carbon foams. Based on this model a phenomenological relationship between the strain-rate and the compressive strength, calibrated on an impact test at one speed, was used. The stress-strain curves obtained were then validated on different velocity impact test computations, allowing a high adherence between the experimental results and the numerical analyses. The material model did not work correctly for the reinforced sandwich panel case simulations. In fact, the erosion based only on the maximum compression gave optimistic results in terms of kinetic energy dissipation. Considering the more complex strain field, the material model was completed by the tensile limits emerged by the three points flexural measurements. Thanks to this refinement the model was able to reproduce the material behaviour in a realistic manner and calculate the bullet's velocity loss within an $11 \%$ error.

\section{Mechanical characterization}

\subsection{Uniaxial stress and uniaxial strain compression experiments}

Several tests according to [4] were performed to measure the material behaviour in the case of uniaxial stress. The specimens reached ultimate failure with very low deformation values and showed a sudden loss in load bearing capability for strains value of about $1.5 \%$. In spite of this, confined compression experiments demonstrated a major change in the material behaviour and a wide extension of the load capability up to very large strains: $50 \%$ and $80 \%$ respectively, depending on the foam density, as reported in Figure 1.

Under confined loading condition, these foams presented energy absorption much higher than in the case of simple compression, due to the extended crushing plateau. This latter behaviour represents a typical feature of brittle foams which reach a densification strain represented by the steep part of the curves depending on material density. The measured values are in accordance with the commonly reported ones [1].

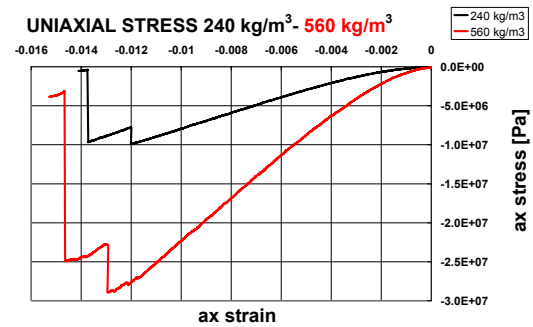

(a)

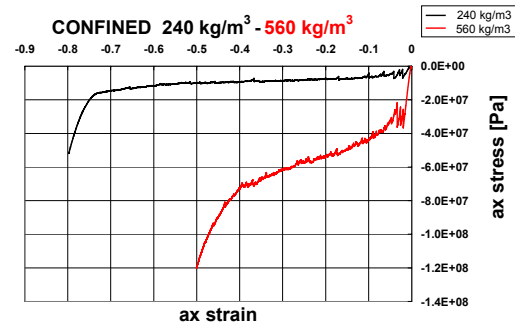

(b)

Figure 1: $\quad$ Comparison of stress-strain curve in the case of uniaxial stress (a) and in case of uniaxial strain for both foam densities (b). 


\subsection{Three points flexural tests}

Considering that, although traditional direct methods to measure tensile strength may be utilized, usually brittle porous materials present significant statistical scatter [5], flexural testing has been performed.

The tests have been carried out according to standards used for composites and for brittle materials. The results obtained following the ASTM B 528 - 05 "Standard Test Method for Transverse Rupture Strength of Metal Powder Specimens" and the D 7264/D 7264M - 07 "Standard test Method for Flexural Properties of Polymer Matrix Composite Materials", are comparable. The measures have been repeated on four specimens for each density which showed a good repeatability. This despite the high brittleness of the carbon foams, which implies easy micro-structural damaging during machining of the specimens. For this reason it is reasonable that the results are somehow pessimistic.

Table 1: $\quad$ Tensile material properties obtained by three point flexural tests.

\begin{tabular}{l|c|c}
\hline Property & $240 \mathrm{~kg} / \mathrm{m}^{3}$ foam & $560 \mathrm{~kg} / \mathrm{m}^{3}$ foam \\
\hline Tensile Strength [MPa] & 0.8 & 6.7 \\
\hline Maximum Tensile strain & 1.8 & 0.25 \\
\hline
\end{tabular}

\section{Ballistic impacts}

Two different kinds of ballistics experiments were performed. They differ mostly for the bullet mass, shape and for the impactor diameter over target thickness ratio. In both cases a compressed air gun to accelerate a sabot was used, and the impacts were recorded with a digital high speed imaging system able to operate at frame intervals of $10 \mu \mathrm{s}$. In both cases the bullet impacted perpendicularly the target.

\subsection{Spherical steel bullet}

The bullet was a $5 \mathrm{~mm}$ diameter, $0,5 \mathrm{~g}$ mass steel sphere, which impacted perpendicular a foam solid block of $50 \times 50 \times 40 \mathrm{~mm}$, simply held on the opposite face (Figure 2). The impact speed was $75 \mathrm{~m} / \mathrm{s}, 210 \mathrm{~m} / \mathrm{s}$ and $240 \mathrm{~m} / \mathrm{s}$. For each speed several tests were performed. The experiments were recorded and the hole depth measured. In all the cases, for both foams the damage was limited to the dimension of the bullet and sometimes the bullet was entrapped into the foam. The recorded video and the analyzed samples showed that the foam underwent uniaxial strain and that the foam was compressed until becoming dust, like in a confined compression experiments. The uniaxial strain condition is typical of high speed impacts [6] and it increases the kinetic energy dissipative performances of the foam. The measured hole depths are reported in Table 2. 


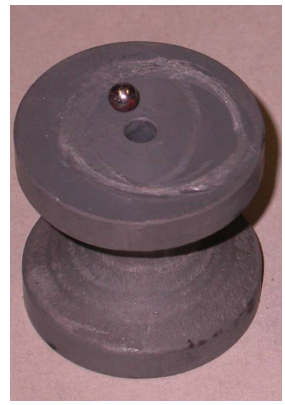

(a)

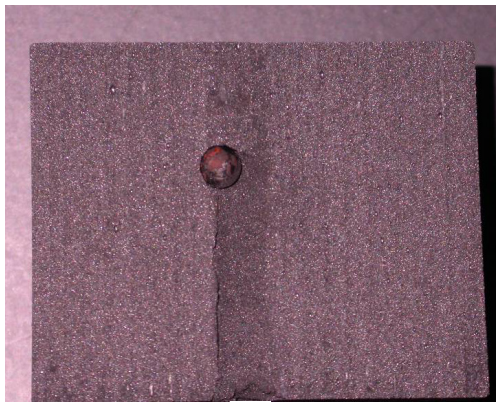

(b)

Figure 2: $\quad$ Bullet completed by the sabot (a) used in the air gas gun to impact the carbon foam samples (b).

Table 2: $\quad$ Spherical steel bullet impact experimental results.

\begin{tabular}{c|c|c}
\hline Foam density $\left[\mathrm{kg} / \mathrm{m}^{3}\right]$ & Impact velocity $[\mathrm{m} / \mathrm{s}]$ & Hole depth $[\mathrm{mm}]$ \\
\hline 240 & 210 & 22 \\
\hline 240 & 240 & 28 \\
\hline 240 & 75 & 4 \\
\hline 560 & 210 & 8 \\
\hline 560 & 240 & 9 \\
\hline
\end{tabular}

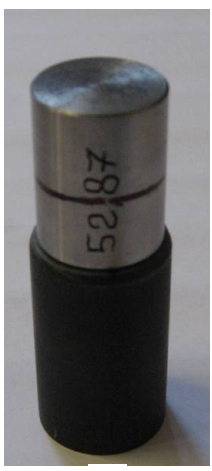

(a)

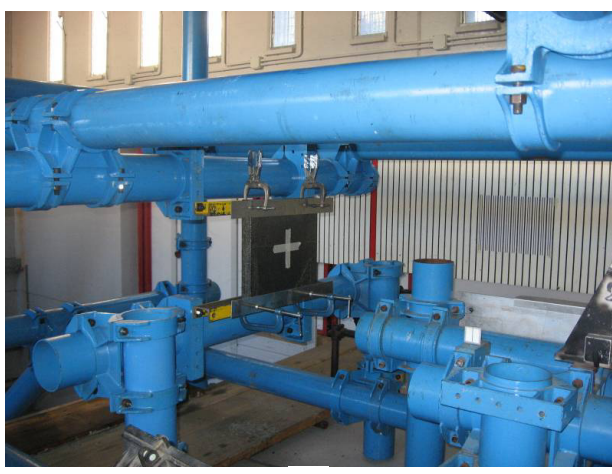

(b)

Figure 3: Carbon reinforced sandwich foam panel case bullet and test facility.

\subsection{Carbon fibre reinforced sandwich panel case}

The other tests were performed using a $400 \mathrm{~mm}$ x $400 \mathrm{~mm}$ x $40 \mathrm{~mm}$ reinforced carbon fibre panel hit by a $93 \mathrm{~g}$ and a $53 \mathrm{~g}$ steel cylindrical bullet (diameter 22 $\mathrm{mm}$, height $40 \mathrm{~mm}$ ). The external carbon fibre skins were made by a satin fabric: 2 plies were on the front face while the back face was covered by 4 plies. The 
carbon composite outer skin simply absolved the dust containing function, allowing at the same time the foam to best perform by limiting the structure flexure. It doesn't have any noticeable ballistic effect. The impactor speed was measured by a software which allowed the measurement of the movement of the same point on different recorded frame. Since the bullet was never stopped by the panel the residual velocity after target trespassing was measured and used as benchmarking for numerical simulations. The results are reported in Table 3.

\section{Experimental-numerical results comparison}

The simulation of the impacts was performed using LS-Dyna 971 r. 3.2.1 in double precision mode. This is a commercial state of the art software, particularly suited for transient non linear dynamics mechanical interaction modelling such as impacts, crashes and penetrations. The models development as well as material implementation and calibration followed an iterative revision process while the understanding of the experimental evidences was in progress (see Figure 4).

Table 3: $\quad$ Carbon reinforced sandwich panel impacts results.

\begin{tabular}{l|c|c|c|c|c|c|c}
\hline $\begin{array}{l}\text { Foam } \\
\text { density } \\
{\left[\mathrm{kg} / \mathrm{m}^{3}\right]}\end{array}$ & $\begin{array}{c}\text { Impactor } \\
\text { mass }[\mathrm{g}]\end{array}$ & \multicolumn{3}{|c|}{ Velocity [m/s] } & \multicolumn{3}{c}{ Energy [J] } \\
\hline 560 & 93 & 245 & 191 & 22.2 & 2801 & 1696 & 39.4 \\
\hline 240 & 53 & 179 & 158 & 11.5 & 846 & 663 & 21.6 \\
\hline
\end{tabular}

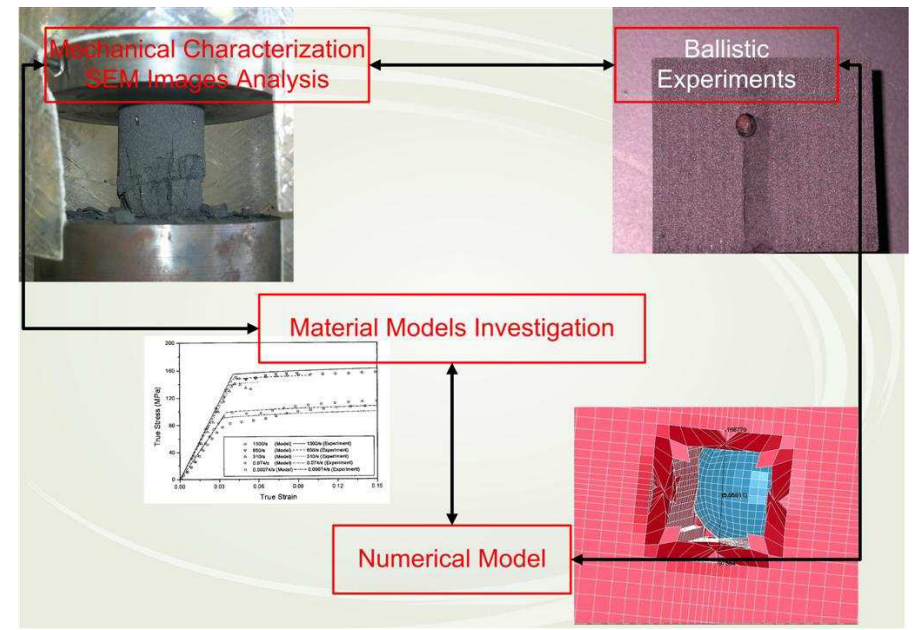

Figure 4: Logic scheme of research development. 


\subsection{Foam material model development}

The model of the material was developed basing on the results of the ballistic tests and of the characterization measurements. Even considering the performances offered by the material in the case of confined uniaxial compression, the quasi-static properties were not in accordance with the kinetic energy dissipative ones showed in the ballistic experiments. Therefore to consider the strain rate effect a micromechanical model typical of the ceramics material has been used. In fact these materials, despite the brittle nature common with the considered foams, exhibit an evident compression strength dependency by the strain rate due to the small cracks dynamical growth [7]. These small cracks nucleate by inclusions and pores of same size of the foam cells. The micromechanical model has been checked, by applying it for the limit condition of quasi static load. This was possible by a previous measurement of the materials fracture toughness. The results were in an acceptable range with the theoretical prediction. Basing on this comparison and on the fact that phenomenological relationships for strain rate dependency native for certain materials are often used for different ones [8] an expression used for ceramics [9] was adopted (see eqn.(1)).

$$
\sigma=\sigma_{c 0}+B \cdot \dot{\varepsilon}^{N}
$$

In this equation $\sigma$ is compressive strength, $\dot{\varepsilon}$ is the strain rate the exponent $\mathrm{N}$ is $1 / 3$ which is a common value for these materials while $B$ is a material empiric parameter.

By the mean of this relationship different stress-strain curves were calculated basing on the quasi static confined ones, varying the B coefficient. Therefore an Ls-Dyna material kind was chosen in its library able to include different stress strain curves described by points for compressive and tensile conditions. This is material 83 "Mat Fu Chang Foam" and it has been already used in the automotive [10] and in the aerospace [11] fields. To include the fragile behaviour, the material model has been completed by erosion criteria as a limit on the maximum principal strain which corresponds to the value identified as the densification strain. Reached this point the material becomes dust and is free to evacuate on the back of the bullet and/or through the target. Therefore once the maximum principal strain gets to the limit the corresponding element is deleted and a new contact surface is defined by the "contact eroding surface to surface" algorithm chosen. The numerical model has been calibrated in the B coefficient referring to a single test spherical bullet impact, at the highest velocity. Once the $B$ value has been fixed for each foam, the same model has been used to reproduce all the experiments at the different velocities. The comparison between numerical and experimental measurements of the hole in the target showed a good agreement. The maximum difference was $7.5 \%$, as reported in Table 4, and the general physical behaviour has been well reproduced with a limited failure due to confined compression (see Figure 5). Additional computations were performed using higher mesh refinements, and showed good consistency of the results. 
Table 4: Numerical vs. experimental results on a block of foam and spherical impactor. The results refer to the standard mesh used and the bold data refer the experiments used for the B parameter calibration.

\begin{tabular}{c|c|c|c}
\hline \multirow{2}{*}{ Foam density } & $\begin{array}{c}\text { Impact Velocity } \\
{[\mathrm{m} / \mathrm{s}]}\end{array}$ & $\begin{array}{c}\text { Std mesh-hole depth } \\
{[\mathrm{mm}]}\end{array}$ & $\begin{array}{c}\text { Experiment hole depth } \\
{[\mathrm{mm}]}\end{array}$ \\
\hline \multirow{3}{*}{ Low } & $\mathbf{7 5}$ & 4.3 & 4 \\
\cline { 2 - 4 } & 210 & 23 & 22 \\
\cline { 2 - 4 } & $\mathbf{2 4 0}$ & $\mathbf{2 8}$ & $\mathbf{2 8}$ \\
\hline \multirow{2}{*}{ High } & 210 & 8 & 8 \\
\cline { 2 - 4 } & $\mathbf{2 4 0}$ & $\mathbf{8 . 9}$ & $\mathbf{9}$ \\
\hline
\end{tabular}
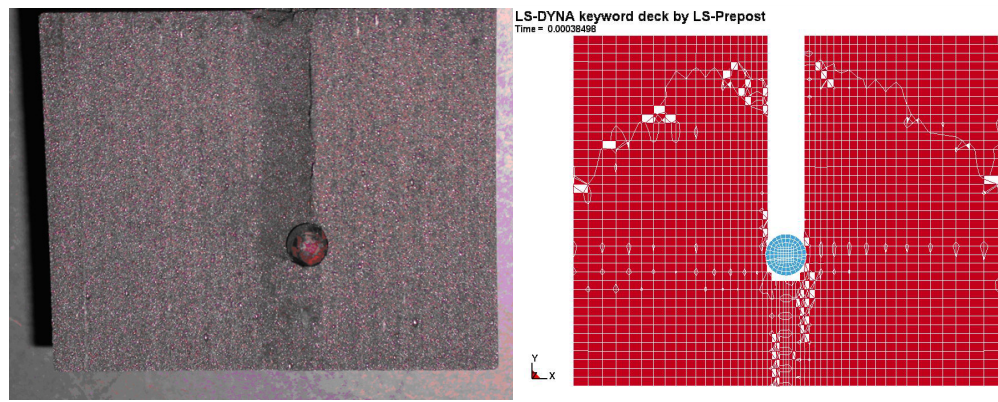

Figure 5: Section plane view of the sample and of the FEM model in the case of impact at $240 \mathrm{~m} / \mathrm{s}$ against the low density foam.

Table 5: $\quad$ Numerical vs. experimental results on sandwich panels.

\begin{tabular}{c|c|c|c|c}
\hline $\begin{array}{c}\text { Foam } \\
\text { density }\end{array}$ & $\begin{array}{c}\text { Bullet } \\
\text { mass }[\mathrm{g}]\end{array}$ & $\begin{array}{c}\text { Impact Velocity } \\
{[\mathrm{m} / \mathrm{s}]}\end{array}$ & $\begin{array}{c}\text { Experimental residual } \\
\text { impactor velocity }[\mathrm{m} / \mathrm{s}]\end{array}$ & $\begin{array}{c}\text { Computed residual } \\
\text { impactor velocity }[\mathrm{m} / \mathrm{s}]\end{array}$ \\
\hline Low & 53 & 179 & 158 & 144 \\
\hline High & 93 & 245 & 191 & 212 \\
\hline
\end{tabular}

To consider the different mechanical stress which involved the foam in the sandwich panel case, the material model has been completed with the tensile properties measured by the three point flexural tests. In this case reached the maximum tensile stress and deformation, the element wasn't anymore able to bear this kind of load but was not deleted from the mesh. This has been done to allow the densification of the fragmented material contained by the external carbon composite skins. The numerical results represented well the physical evidence (see Figure 6) and the difference in the residual bullet velocity is limited in $11 \%$ as reported in Table 5. The main difference is due to the lack of the erosion criteria in tension, so that the visually broken area is less extended in the simulations than in the experiments. 

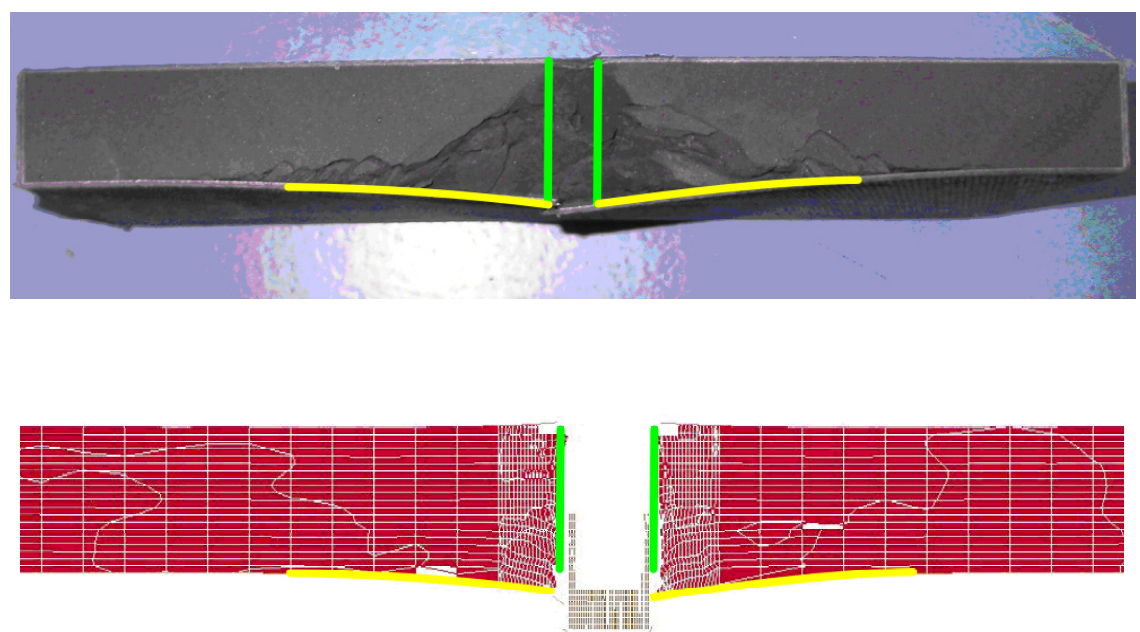

Figure 6: Comparison of the damaged area caused by the bullet impact. The numerical result underestimates the extension due to the missing erosion criteria for tensile strain. Anyhow, the highlighted sides show how the hole copes with the impactor dimensions and that the rear side flexure has been realistically reproduced. The two pictures are not to the same scale.

\section{Conclusions}

It is possible to affirm that the carbon foams are able to involve a much higher quote of deformation energy in the uniaxial strain process than in the uniaxial stress one. This capability together with the compressive strength strain rate dependency allow good ballistic results considering the material low density and the rebound control offered in case of small fragments. Considering the other properties showed by this material it could be successfully used to develop structures able to absolve multiple functions at the same time: structural and protective ones, as well as thermal protection and sound absorbing represent the fields of application of them. For these reasons the use presented in [3] seems to be very interesting and meaningful. Another investigation area to develop could be the addition of other materials into the cellular structure to improve the foams performances for some specific applications.

\section{References}

[1] Gibson, L.J., Ashby, M.F., Cellular solids, structure and Properties, Second Edition, Cambridge (1999).

[2] M.D. Sarzynski, Carbon Foam Characterization: Sandwich Flexure, Tensile and Shear Response, Master Thesis, (2003). 
[3] M. Grujicic, B. Pandurangan, C.L. Zhao, S.B. Biggers, D.R. Morgan, Hypervelocity impact resistance of reinforced carbon-carbon/carbon-foam thermal protection systems, Applied Surface Science, 2005.

[4] RILEM TC 148-ssc: Test Methods for compressive softening, Test method for measurement of the strain-softening behaviour of concrete under uniaxial compression, 2001.

[5] G. Quinn; "Encyclopaedia of Materials: Science and Technology", 2001 Elsevier Science Ltd.

[6] M.A. Meyers, Dynamic Behaviour of Materials, 1994, John Wiley and Sons, Inc.

[7] G. Ravichandran, G. Subash, A Micromechanical Model for High Strain Rate Behaviour of Ceramics, Intl. J. Solids Structures, Vol43. No17718 pp 2627-2646; (1995) Elsevier Science Ltd.

[8] Chen W., Lu F., A technique for dynamic proportional multiaxial compression on soft materials, Exp Mech 2000, 40: 226-230.

[9] J. Lankford, Mechanism Responsible for Strain - Rate - Dependent Compressive Strength in Ceramic Materials, Communications of the American Ceramic Society, (1981).

[10] Sambamoorthy, Halder, Characterization and Component Level Correlation of Energy Absorbing PU Foams using Ls-Dyna Material Models, Lear Corporation.

[11] Chocron, Walker, Nicholls, Dannemann, Anderson, Analytical model of the confined compression Test Used to Characterize Brittle Materials; Journal of Applied Mechanics, March 2008 vol 75. 